\title{
Diabetic Foot Prevention: Repeatability of the Loran Platform Plantar Pressure and Load Distribution Measurements in Nondiabetic Subjects during Bipedal Standing-A Pilot Study
}

\author{
Martha Zequera, ${ }^{1}$ Leonardo Garavito, ${ }^{2}$ William Sandham, ${ }^{3}$ Juan Camilo Bernal, ${ }^{1}$ \\ Ángela Rodríguez, ${ }^{1}$ Luis Camilo Jiménez, ${ }^{1}$ Andrés Hernández, ${ }^{1}$ Carlos Wilches, ${ }^{1}$ and Ana \\ Cecilia Villa ${ }^{1}$
}

${ }^{1}$ Bioengineering Signal Analysis and Image Processing Research Group (BASPI), Department of Electronics, Pontificia Universidad Javeriana, Bogotá 110231, Colombia

${ }^{2}$ School of Medicine, Pontificia Universidad Javeriana and San Ignacio Hospital, Bogotá 110231, Colombia

${ }^{3}$ Scotsig, 40 Westbourne Gardens, Glasgow G12 9PF, UK

Correspondence should be addressed to Martha Zequera, mzequera@javeriana.edu.co

Received 17 September 2010; Accepted 14 February 2011

Academic Editor: David Hamilton

Copyright (c) 2011 Martha Zequera et al. This is an open access article distributed under the Creative Commons Attribution License, which permits unrestricted use, distribution, and reproduction in any medium, provided the original work is properly cited.

\begin{abstract}
This study was designed to assess the repeatability of the Loran Platform and evaluate the variability of plantar pressure and postural balance, during barefoot standing in nondiabetic subjects, for future diabetic foot clinical evaluation. Measurements were taken for eight nondiabetic subjects ( 4 females, 4 males, aged $47 \pm 7.2$ years) who had no musculoskeletal symptoms. Five variables were measured with the platform in the barefoot standing position. Ten measurements were taken using two different techniques for feet and posture positioning, during three sessions, once a week. For most measurements, no significant effect over time was found with Student's $t$-test $(P<.000125)$. The ANOVA test of statistical significance confirmed that measurement differences between subjects showed higher variations than measurements taken from the same subject $(P<.001)$. The measurements taken by the Loran Platform system were found to be repeatable.
\end{abstract}

\section{Introduction}

Diabetes mellitus, or simply diabetes, is a chronic disease recognized as a growing global public health problem. It is one of the main causes of premature mortality worldwide, and it has been predicted that the number of diabetic patients will increase from an estimated 135 million in 1995 to 300 million in 2025 [1]. A substantial increase in the prevalence of type 2 diabetes has been identified, which has been related to lifestyle and diet issues, combined with longer survival, obesity, low physical activity, and other factors; also, a significant proportion of people with type 2 diabetes remain undiagnosed. This group of subjects is at high risk of developing complications, including nephropathy, retinopathy, and neuropathy, the latter can cause foot ulcerations and, in patients with abnormally high plantar pressures, foot amputations. Biomechanical factors are important because feet are always subject to dynamic loads $[1,2]$.

Several studies have identified aspects of plantar pressure and characteristics during gait and standing, in barefoot and in-shoe patterns $[3,4]$. At least one study has analyzed gender comparisons to detect or prevent foot pathologies [5]. It has been demonstrated that during prolonged periods of immobility, individuals alter their postural positions to diminish musculoskeletal discomfort due to mechanical loads, especially over joint tissues [6].

Pressure systems are commonly used to record and analyze subject data, but no standardization exists regarding a system to measure gait and standing foot parameters; in-shoe and platform are the two systems commonly used [7]. In order to improve results, several studies have been carried out in which the foot has been divided into several regions based 


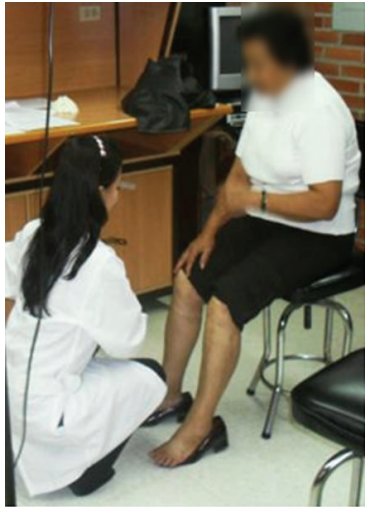

(a)

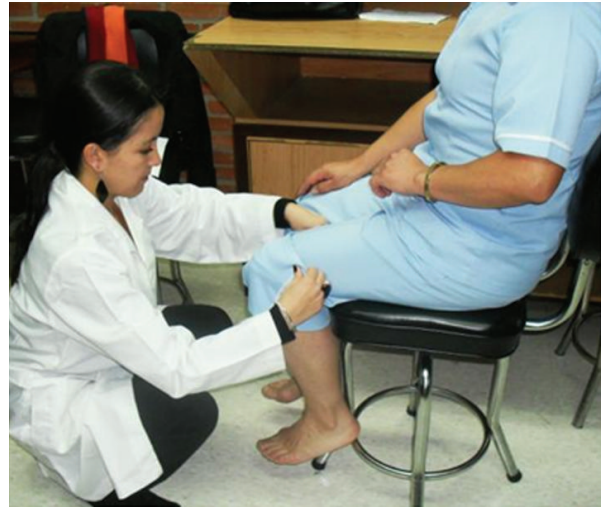

(b)

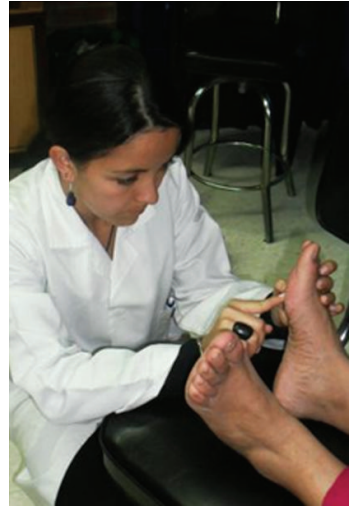

(c)

Figure 1: Physical examination of a subject prior to the study.

on distinct anatomical areas: midfoot, forefoot, and hallux [8]. Previous studies have used a variety of systems and techniques to analyze foot pressures and assess repeatability of the system used in these studies. The Emed1 system is one of the most common devices for barefoot pressure measurement. Variability measurements are considered to be useful for future applications.

Despite the use of modern and pioneering technologies to record pressure, the repeatability of plantar pressure and postural balance measurements must be evaluated quantitatively, in order to develop future clinical studies for application in clinical settings, which would improve clinical diagnostic evaluations.

The pilot study reported in this paper seeks to evaluate a new plantar pressure measurement system for early stage diagnoses of the diabetic foot. The hypotheses used in this study were as follows.

(H1) The repeatability of the Loran Platform during three sessions, once a week, on the same subject, did not report any significant variability.

(H2) Plantar pressure and postural balance measurement variability between subjects is significantly greater than intrasubject variability.

In Section 2, the materials and experimental methodology used in this study are described. Data and statistical analyses are then documented in Section 3, including the use of Student's $t$-test and also ANOVA analyses. Sections 4 and 5 contain a discussion of the results and conclusions from the study, respectively.

\section{Materials and Methodology}

In order to assess the repeatability of the Loran Platform and evaluate plantar pressure and postural balance variability in the barefoot standing position in nondiabetic subjects, eight volunteers ( 4 females and 4 males, aged $47 \pm 7.2$ years) were recruited for this pilot study (Figure 1). All subjects signed an informed consent form and were free of musculoskeletal symptoms at the time of testing. Approval was obtained by the local Medical Research Ethics Committee.

Three test sessions were conducted with each subject, 7 to 10 days apart, at approximately the same time of day. Subjects conformed to the following criteria: (a) mainly in the age range 30-60 years, (b) ranked with a normal body mass index, and (c) non-diabetic; in addition, subjects were excluded if they had experienced osteomuscular symptoms, injuries, obesity, peripheral neuropathy, vasculopathy, or other systemic pathological conditions which could affect measurements, such as diabetes, multiple sclerosis, or intervertebral disc disorders.

A pressure distribution platform (Loran Engineering SrL, Italy) with 2304 resistive sensors and a sampling frequency of $30 \mathrm{~Hz}$ was used to collect point of maximum load pressure (PML), percentage of load for each foot (lateral load distribution-LLD), body barycenter (BB), foot barycenters (B), and percentage of anterior load (ALD) and posterior load (PLD) measurement patterns during barefoot standing, using the Footchecker 4.0 Software to measure these variables. The platform was mounted in the center of an engineering lab with constant access to the complete experimental setup: a computer, a standing lamp, and the guides (Figure 2). At the beginning of every session, a calibration procedure was performed by recording reference points using the $3 \mathrm{D}$ guide.

Two different techniques were used for feet and posture positioning during the test sessions. Ten measurements were taken using each technique (Figure 3). The first method consisted of a 3D wooden frame placed on the platform to control foot and body position, following the anatomical position. The second method consisted of a $2 \mathrm{D}$ guide drawn on the platform, following the same geometry of the 3D guide (Figure 3 ).

Thirty measurements were obtained from each subject over the course of three sessions. Mean and standard deviation of 10 measurements per session were calculated, and Student's $t$-test was used to assess the statistical repeatability of measurements between the three sessions, so as to evaluate effects produced by time. The ANOVA test was used to 


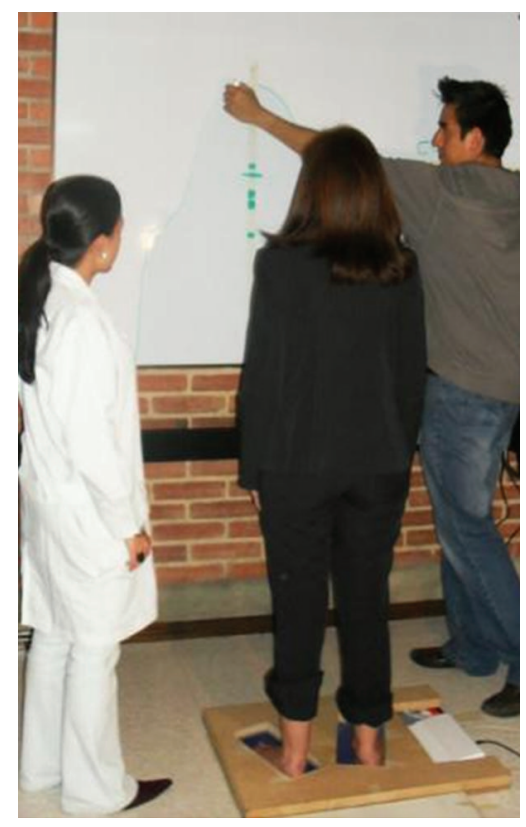

(a)

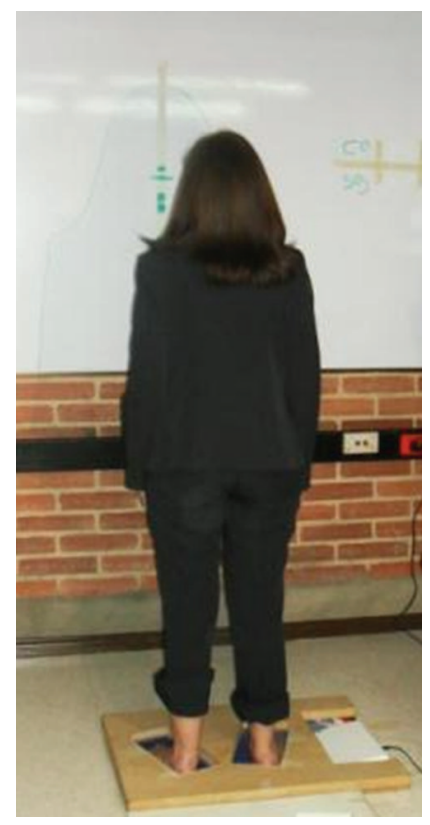

(b)
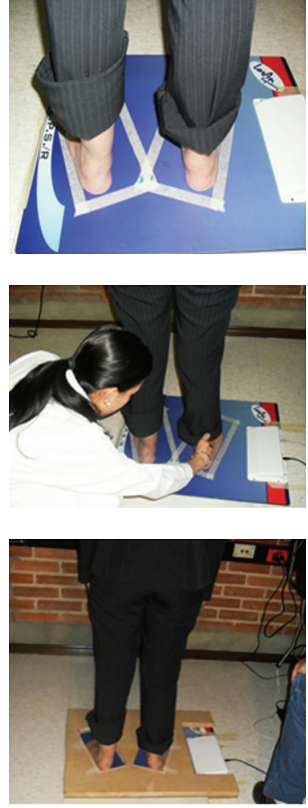

(c)

FIgURe 2: Procedure to assess the repeatability of the Loran Platform using two different techniques for feet and posture positioning.

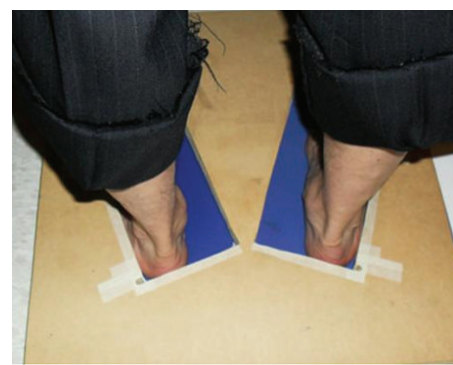

(a)

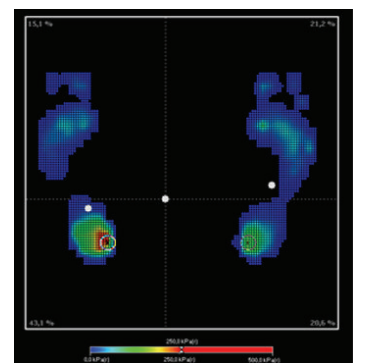

(b)

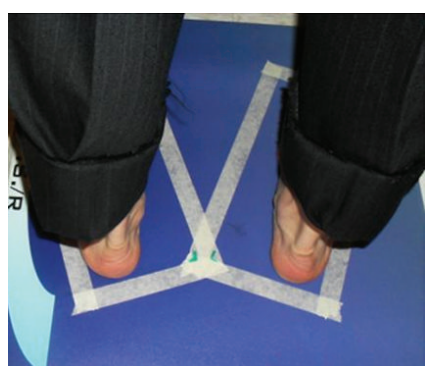

(c)

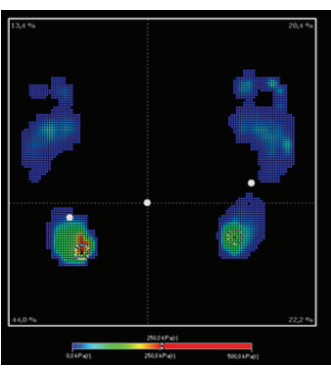

(d)

FIGURE 3: Two techniques following the anatomical position of the foot: (a) 3D wooden frame; (b) digital image of the pressure measurement with the 3D guide; (c) 2D frame; (d) digital image of the pressure measurement with the 2D guide.

investigate the variability of plantar pressure and postural balance in all male and female subjects with the $3 \mathrm{D}$ guide and the $2 \mathrm{D}$ guide techniques, during the three sessions in order to evaluate the repeatability of the system with the two techniques. 120 measurements were recorded for each group with each technique.

Selection criteria of the $P$ value $(P>.000125)$ are as follows.

(1) Three simultaneous comparisons were carried out. Each comparison had a $P$-value of $5 \%$. During analysis, it was necessary to adjust the $P$-value for the number of comparisons.

(2) The adjustment made was

$$
P \text { value }_{\text {comparisons }}=.05^{c},
$$

where $c$ is the number of comparisons.
As a result of the adjustment,

$$
P \text { value } \text { comparisons }=.05^{3}=.000125 \text {. }
$$

All subjects were given time to become acquainted with the process of adequately positioning their feet on the platform. Prior to pressure measurements, a medical doctor examined the subjects, focusing on their feet. Subjects, were asked to be barefoot, have no objects in their pockets and wear comfortable clothes in order to prevent inaccurate measurements.

Three sessions took place at the same time and place for each subject and were held once a week. Each session consisted of ten measurements using the 3D guide, which were taken at the start of the session. Subjects received instructions on how to stand on the platform and proceeded with their first attempt, controlling the position of the feet with the $3 \mathrm{D}$ guide. 
A standing lamp was lit behind subjects to draw their silhouettes in front of them in order to control body position for the ten measurements. Afterwards, 10 measurements were taken with the platform using the $3 \mathrm{D}$ guide. Subjects had to walk up and down the platform for each measurement. During these ten measurements, a research assistant observed and guided subjects regarding body and feet positions. Once the ten measurements were completed, the $3 \mathrm{D}$ guide was removed and the same procedure was then followed with the $2 \mathrm{D}$ guide, which was drawn on the platform. A total of twenty measurements were taken each time with each subject, and subjects had to come to the lab three times during three weeks to complete sixty measurements in total: thirty using the $3 \mathrm{D}$ guide and thirty without it (Figure 4).

Student's $t$-test was used to assess the statistical repeatability of measurements between the 60 measurements for each subject (30 using the 3D guide, 30 using the 2D guide, 10 measurements per session during 3 sessions); ANOVA was used to study the variability of the point of maximum load pressure, the percentage of load for each foot, the body barycenter, the foot barycenter, and the percentage of anterior load and posterior load, among all subjects during the three sessions (480 measurements).

\section{Results}

Results are reported in this section for Student's $t$-test by gender and the ANOVA statistical analysis. These were performed to determine if measurements of the point of maximum load pressure (PMLx and PMLy), the percentage of loads for each foot (LLD), the body barycenter (BBx and $\mathrm{BBy}$ ), the foot barycenters (Bx and By), and the percentage of anteroposterior loads (ALD-PLD) during barefoot standing, registered by the Loran Platform, are repeatable, using the two techniques. The tables reporting the statistical analysis of Student's $t$-test correspond to subjects with greater and lesser variability in the measurements of plantar pressure and balance control due to time. The ANOVA analysis was performed with the variables that produced satisfactory Student's $t$-test results for all subjects, that is, variables with no significant effect over time and with $P>.000125$. The four male and four female subjects were designated as M1, $\mathrm{M} 2, \mathrm{M} 3$, and M4, and F1, F2, F3, and F4, respectively.

\subsection{Student's t-Test}

\section{1st Technique 3D Wooden Frame-Male Subjects.}

(M1 and M2) Time was not a significant variable since, in the 3 sessions, 9 registered variables reported a $P>$ .000125 for both feet.

(M3) The variable LLD reported $P<.000125$ in the right foot (comparing the data obtained during the 1st measurement session with the data obtained during the $2 \mathrm{nd}$ session and between the $2 \mathrm{nd}$ and $3 \mathrm{rd}$ sessions). For other variables, time is not a significant variable, and $P^{\prime}>.000125$ for both feet.
(M4) Time impacted LLD, ALD, PLD, By, PMLy, and BBy variables in both feet $(P<.000125)$. In Bx, PMLx, and $\mathrm{BBx}$, time did not affect either foot $(P>$ .000125). In Table 1, the values obtained are shown for each variable for subjects M1 and M4.

1st Technique: 3D Wooden Frame-Female Subjects.

(F1) Time was not a significant variable; $97.92 \%$ of the $P$ values for the 9 variables registered in the 3 sessions reported $P>.000125$ for both feet. Only the right foot LLD showed $P<.000125$, indicating variability in the measurements taken from week to week.

(F2) $P<.000125$ was obtained for BBy and for LLD and ALD in the right foot.

(F3) $P>.000125$ for the left foot was reported, while in the right foot, variations were observed in LLD, ALD, PLD, Bx, and By $(P<.000125)$.

(F4) Variations were observed in both feet: variations in $\mathrm{LLD}, \mathrm{By}, \mathrm{BBx}$, and $\mathrm{BBy}$ in the right foot and variations in ALD, LLD, BBx, and BBy in the left foot, in both cases with $P<.000125$. Values obtained for each of the variables for patients F1 and F4 are shown in Table 2.

\section{2nd Technique: 2D Frame-Male Subjects.}

(M1 and M2) Time was not a significant variable since the 9 variables registered in the 3 sessions reported $P>$ .000125 in both feet.

(M3) Time impacted LLD and BBx in both feet and, also, impacted ALD and $\mathrm{Bx}(P<.000125)$ in the right foot; other variables with $P>.000125$ did not show significant differences.

(M4) Time had no impact on Bx, PMLx, and BBx in either foot $(P>.000125)$; LLD and PLD in the left foot and ALD and PMLy in the right foot reported $P>.000125 . P<.000125$, indicating variation in the measurements, was reported for other variables. Table 3 shows values obtained for each variable for M1 and M4 using the 2D frame technique for the measurements.

\section{2nd Technique: 2D Frame-Female Subjects.}

(F1) $91.67 \%$ of the $P$-values registered for the 9 variables in the 3 serial weekly sessions reported $P>.000125$. In By, LLD, and PLD in the right foot and in LLD in the left foot, incidence over time was registered $(P<$ .000125).

(F2) In $81.25 \%$ of the 9 variables registered in the 3 sessions, $P>.000125$ was reported; for LLD and BBx in both feet, for ALD in the left foot, and for PLD in the right foot, a variation in measurements was reported $(P<.000125)$. 

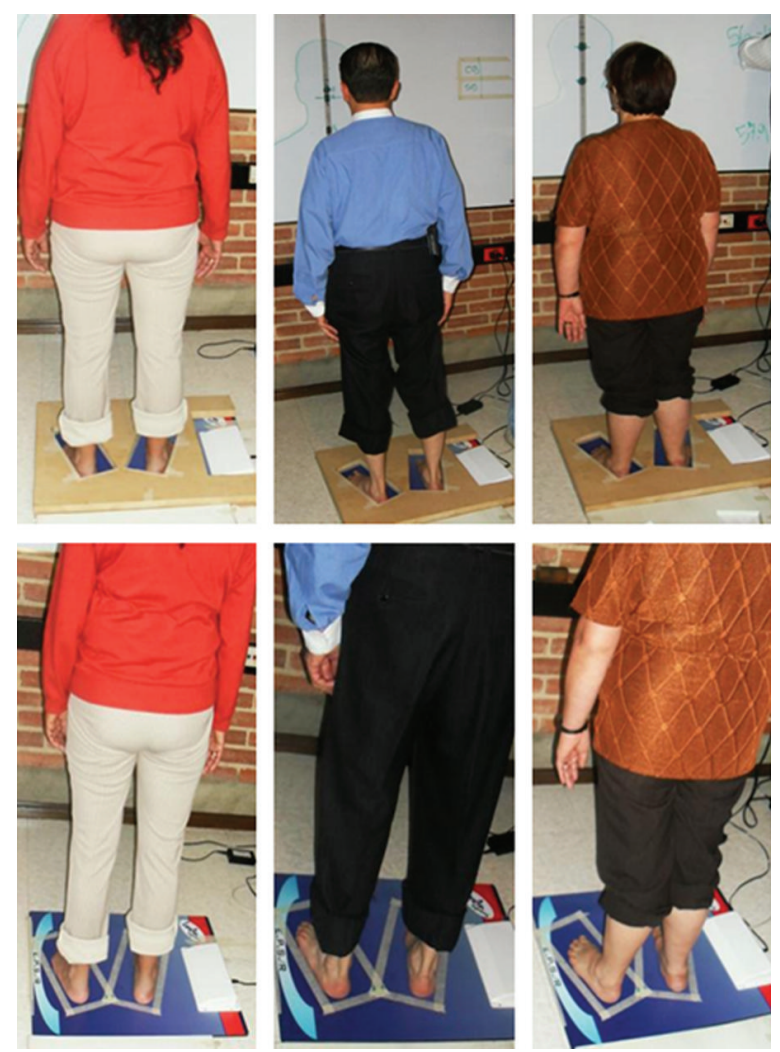

(a)

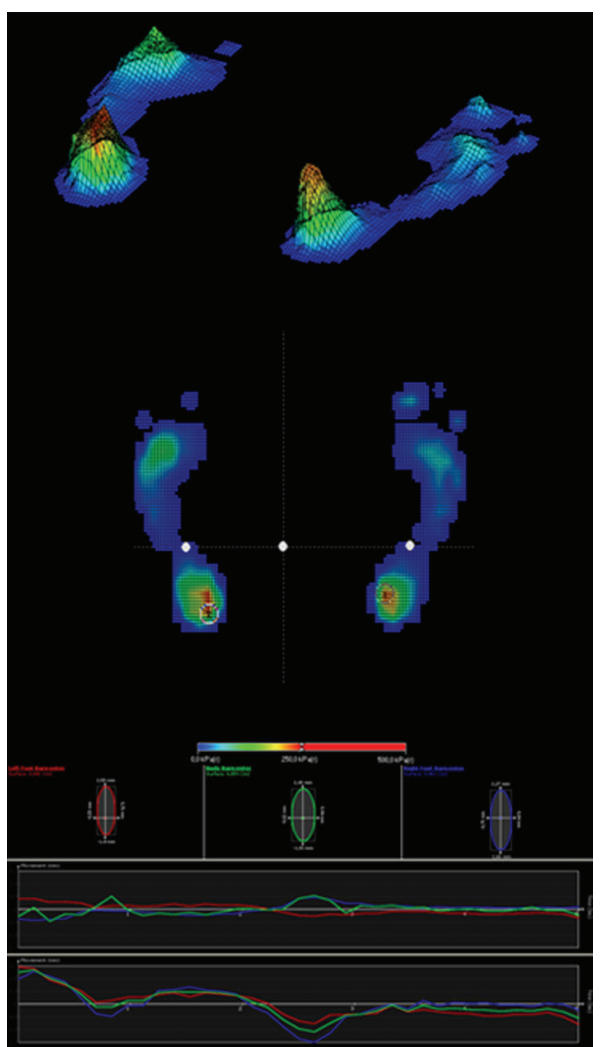

(b)

FIgURE 4: Normal subjects with the 3D guide and 2D guide techniques for pressure measurements.

TABLE 1: Student's $t$-test analysis. Sample of features in male subjects M1 and M4 during 3 sessions with the 3D guide $(P>.000125 \rightarrow$ " + ," $P<.000125 \rightarrow$ “-”).

\begin{tabular}{|c|c|c|c|c|c|c|c|c|c|c|c|c|}
\hline \multirow{3}{*}{$\begin{array}{l}\text { Features } \\
\text { LLD }\end{array}$} & \multicolumn{6}{|c|}{ Subject M1 } & \multicolumn{6}{|c|}{ Subject M4 } \\
\hline & \multicolumn{3}{|c|}{ Right foot } & \multicolumn{3}{|c|}{ Left foot } & \multicolumn{3}{|c|}{ Right foot } & \multicolumn{3}{|c|}{ Left foot } \\
\hline & + & + & + & + & + & + & - & - & + & + & + & + \\
\hline ALD & + & + & + & + & + & + & + & + & + & + & + & - \\
\hline PLD & + & + & + & + & + & + & + & + & - & + & + & + \\
\hline$B x$ & + & + & + & + & + & + & + & + & + & + & + & + \\
\hline By & + & + & + & + & + & + & + & + & - & + & + & - \\
\hline PMLx & + & + & + & + & + & + & + & + & + & + & + & + \\
\hline PMLy & + & + & + & + & + & + & + & + & + & + & + & - \\
\hline $\mathrm{BBx}$ & + & + & + & + & + & + & + & + & + & + & + & + \\
\hline BBy & + & + & + & + & + & + & + & + & - & + & + & - \\
\hline
\end{tabular}

(F3) $79.17 \%$ of the 9 variables registered in the 3 sessions reported $P>.000125$. Variables LLD, BBx, and BBy, in both feet, PLD in the right foot, and By in the left foot reported measurement variations $(P<$ .000125).

(F4) In 77.08\%, $P>.000125$ was reported; for LLD, PLD, $\mathrm{BBx}$, and $\mathrm{BBy}$ in both feet and for By in the right foot, measurement variations were reported $(P<$ .000125). Table 4 shows the values obtained for each variable using the 2D guide for cases F1 and F4.
3.2. ANOVA Analysis. To determine variation among subjects, an ANOVA analysis was performed on variables for which Student's $t$-test was satisfactory for all subjects $(P>$ .000125), taking into account the data obtained in the three sessions for both feet.

\section{1st Technique: 3D Wooden Frame.}

male subjects: Variables Bx, PMLx, and BBx reported $P<.001$ (Table 5), which means there is a greater variability among the subjects. 


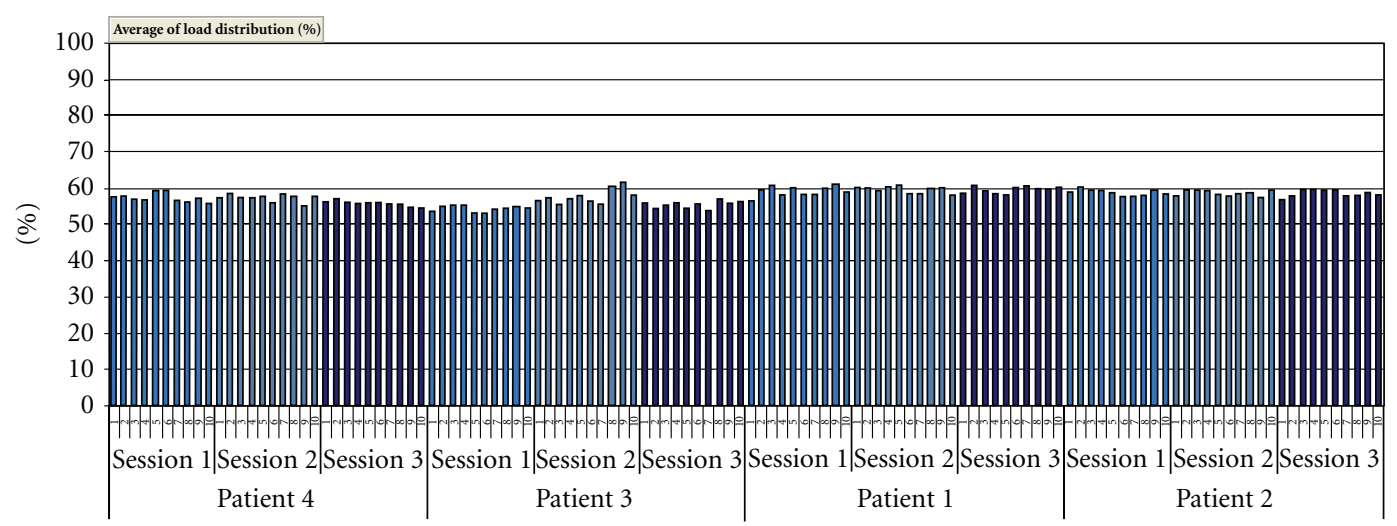

(a) Left foot male subjects

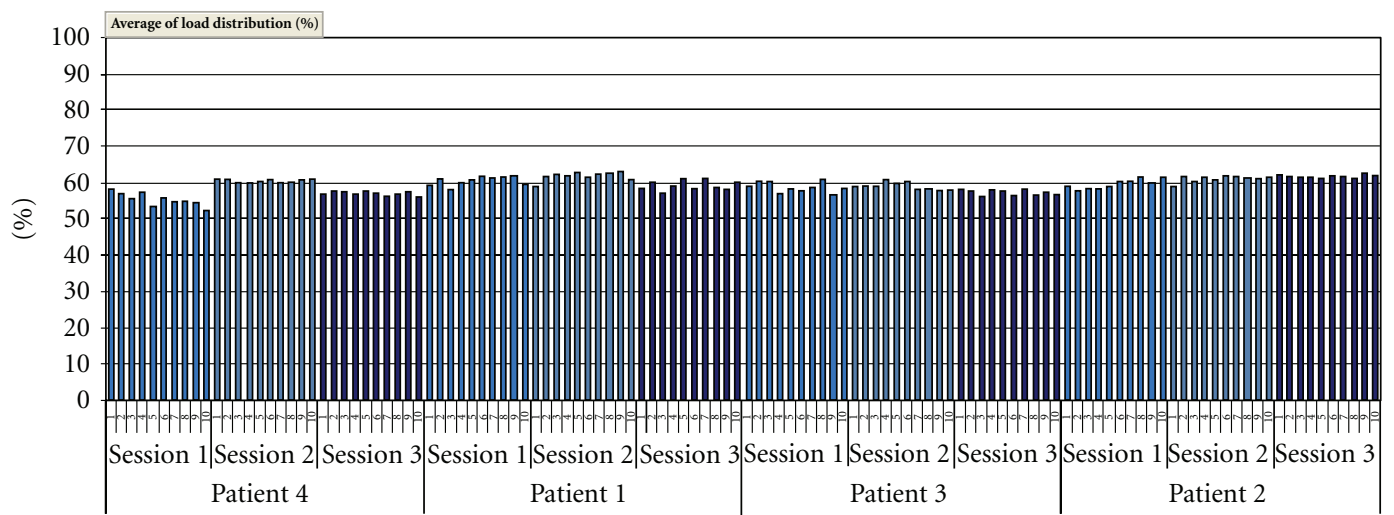

(b) Left foot female subjects

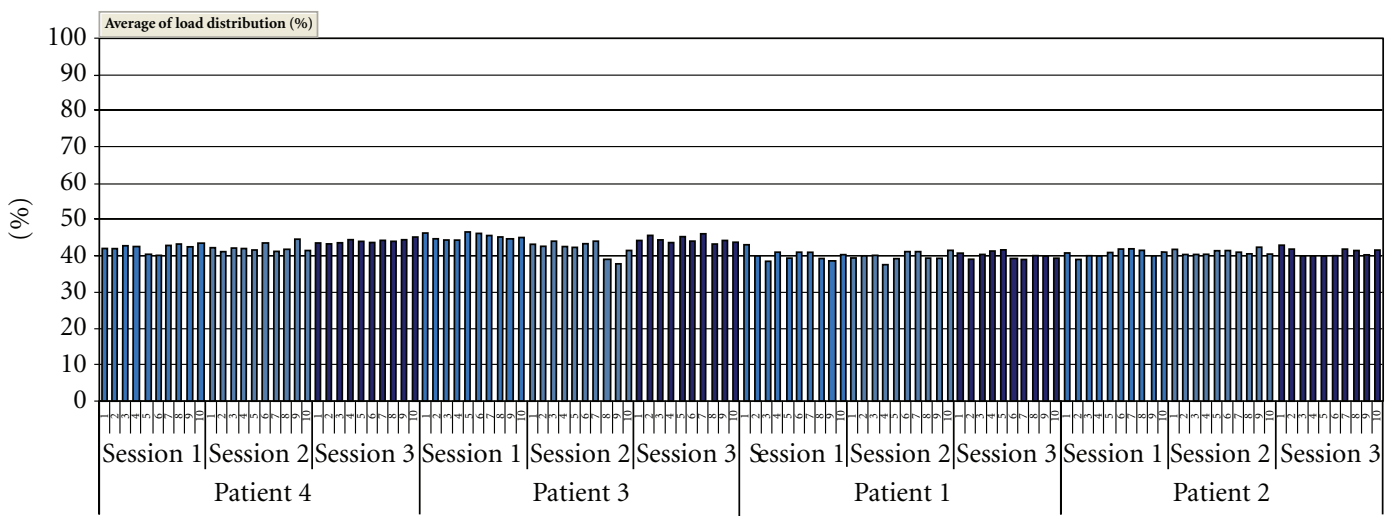

(c) Right foot male subjects

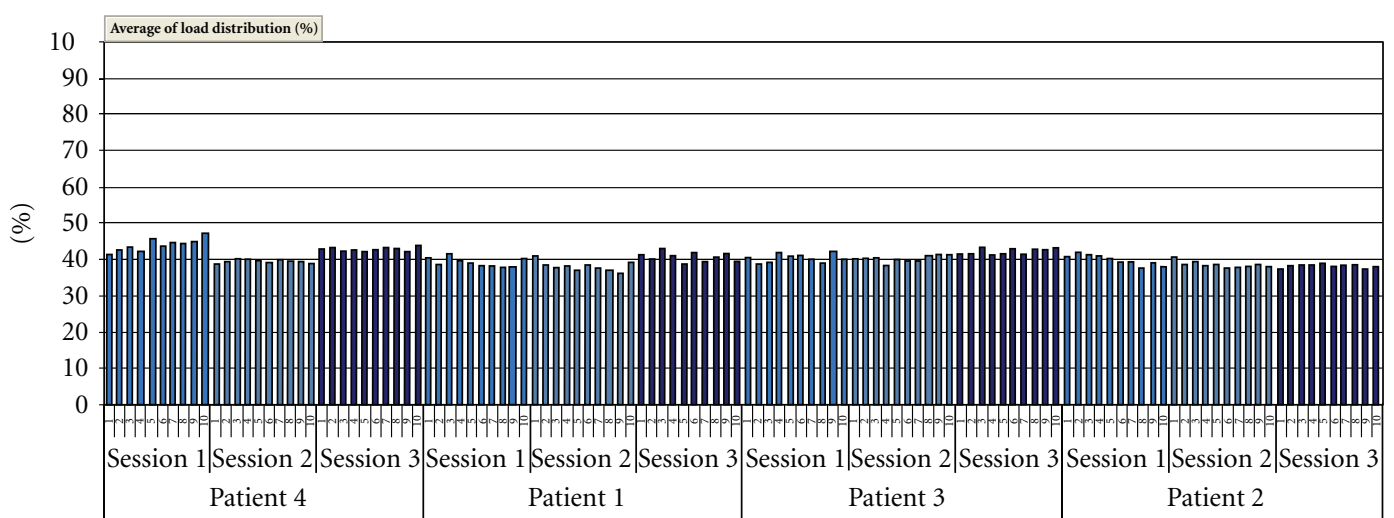

(d) Right foot female subjects

Figure 5: Graphical feature comparison between sessions. Percentage load distribution with 3D Guide. 


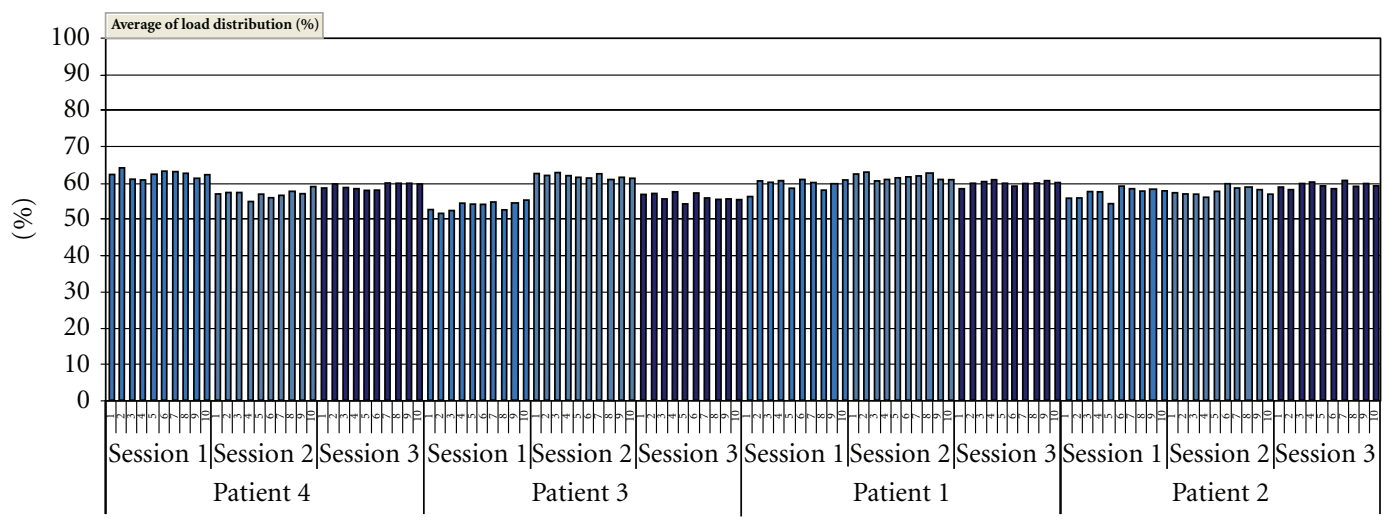

(a) Left foot male subjects

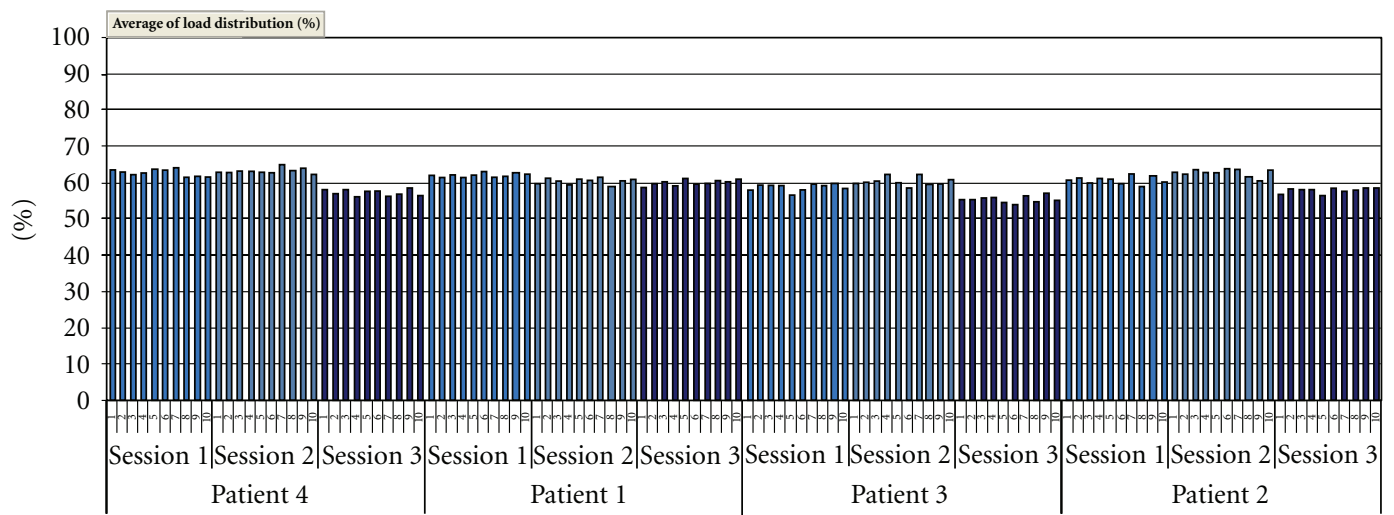

(b) Left foot female subjects

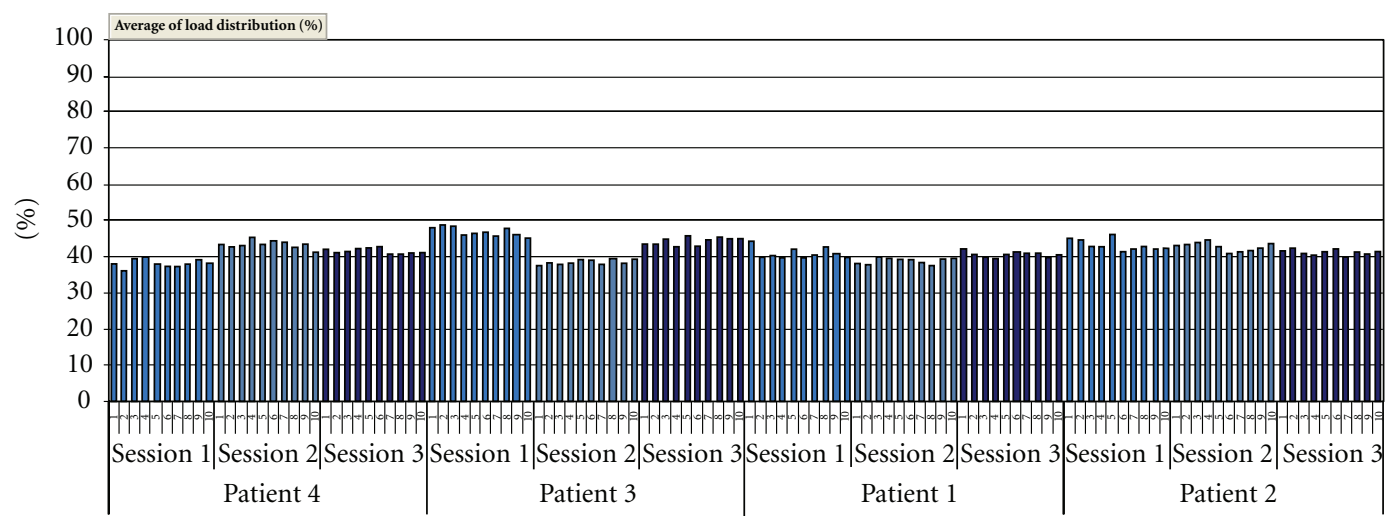

(c) Right foot male subjects

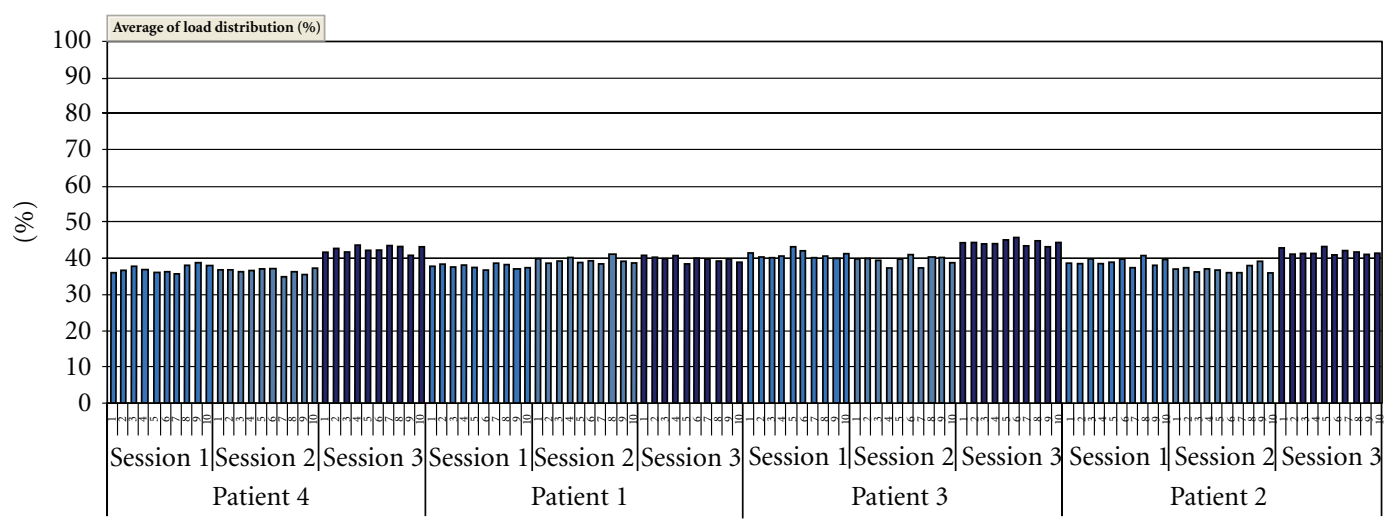

(d) Right foot female subjects

Figure 6: Graphical feature comparison between sessions. Percentage load distribution with 2D Guide. 
TABle 2: Student's $t$-test analysis of features in female subjects F1 and F4 over 3 sessions with the $3 \mathrm{D}$ guide $(P>.000125 \rightarrow$ “ + ," $P<$ $.000125 \rightarrow$ “").

\begin{tabular}{|c|c|c|c|c|c|c|c|c|c|c|c|c|}
\hline \multirow{3}{*}{$\begin{array}{l}\text { Features } \\
\text { LLD }\end{array}$} & \multicolumn{6}{|c|}{ Subject M1 } & \multicolumn{6}{|c|}{ Subject M4 } \\
\hline & \multicolumn{3}{|c|}{ Right foot } & \multicolumn{3}{|c|}{ Left foot } & \multicolumn{3}{|c|}{ Right foot } & \multicolumn{3}{|c|}{ Left foot } \\
\hline & + & - & + & + & + & + & - & + & - & - & + & - \\
\hline ALD & + & + & + & + & + & + & + & - & + & + & + & + \\
\hline PLD & + & + & + & + & + & + & + & + & + & - & + & + \\
\hline $\mathrm{Bx}$ & + & + & + & + & + & + & + & + & + & + & + & + \\
\hline By & + & + & + & + & + & + & + & - & + & + & + & + \\
\hline PMLx & + & + & + & + & + & + & + & + & + & + & + & + \\
\hline PMLy & + & + & + & + & + & + & + & + & + & + & + & + \\
\hline $\mathrm{BBx}$ & + & + & + & + & + & + & + & + & - & + & + & - \\
\hline BBy & + & + & + & + & + & + & - & - & + & - & - & + \\
\hline
\end{tabular}

TABle 3: Student's $t$-test analysis of the features in male subjects M1 and M4 during 3 sessions with the $2 \mathrm{D}$ guide $(P>.000125 \rightarrow$ " + ," $P<.000125 \rightarrow$ “"”).

\begin{tabular}{|c|c|c|c|c|c|c|c|c|c|c|c|c|}
\hline \multirow{3}{*}{$\begin{array}{l}\text { Features } \\
\text { LLD }\end{array}$} & \multicolumn{6}{|c|}{ Subject M1 } & \multicolumn{6}{|c|}{ Subject M4 } \\
\hline & \multicolumn{2}{|r|}{ Right foot } & & \multicolumn{3}{|c|}{ Left foot } & \multirow{2}{*}{$\frac{\text { Right foot }}{-}$} & \multicolumn{5}{|c|}{ Left foot } \\
\hline & + & + & + & + & + & + & & - & + & - & - & + \\
\hline ALD & + & + & + & + & + & + & + & + & + & + & + & + \\
\hline PLD & + & + & + & + & + & + & + & + & + & + & + & + \\
\hline $\mathrm{Bx}$ & + & + & + & + & + & + & + & + & + & + & + & + \\
\hline By & + & + & + & + & + & + & + & + & + & + & + & + \\
\hline PMLx & + & + & + & + & + & + & + & + & + & + & + & + \\
\hline PMLy & + & + & + & + & + & + & + & + & + & + & + & + \\
\hline $\mathrm{BBx}$ & + & + & + & + & + & + & - & - & + & - & - & + \\
\hline BBy & + & + & + & + & + & + & + & + & + & + & + & + \\
\hline
\end{tabular}

Female subjects: variables PMLx and PMLy reported $P<.001$. Table 5(b) shows results obtained by the ANOVA analysis for this case with the $3 \mathrm{D}$ guide.

\section{2nd Technique: 2D Frame.}

Male subjects: most variables showed repeatability improvements between sessions; only PMLy presented $P=.0226>.001$ in the left foot, meaning that measurements per subject were more variable than variability among subjects.

Female subjects: in the case of female subjects, more variables also show repeatability between sessions, one of them (PMLy) with $P=.0822$ (Table 6(b)).

Figures 5 and 6 contain a comparative chart of load distribution patterns for each foot during the three measurement sessions with the group of subjects, differentiating by gender. In Figure 5, the percentage of load distribution with the $3 \mathrm{D}$ guide shows lower variability between right and left feet among subjects during the 3 sessions compared with the trend shown in Figure 6, which shows results obtained using the $2 \mathrm{D}$ guide. $\mathrm{H} 2$ is supported with the ANOVA tables (Tables 5 and 6).

Figure 7 shows the image obtained from the Loran Platform, dividing the foot in segments of greater interest in order to establish the behavioral patterns of the body

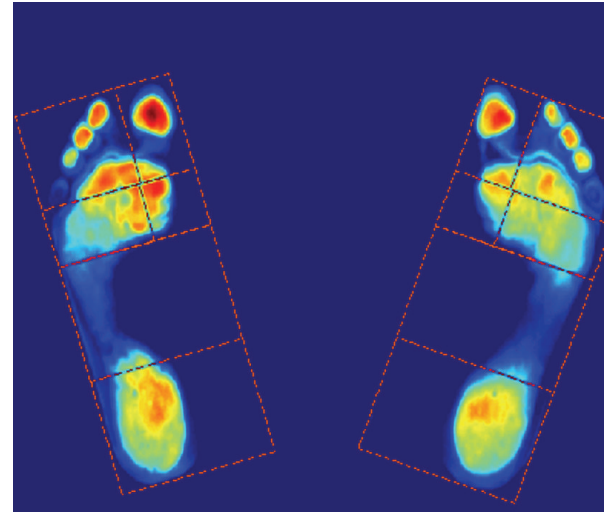

FIgURE 7: Pressure distribution patterns, including maximum pressure.

barycenter, the barycenter of the feet, and the points of maximum pressure of the subjects participating in the study. This image was color modified to highlight the respective distribution patterns (Figures 8, 9, and 10).

A similar behavior is seen between genders with the $3 \mathrm{D}$ guide, as observed with the $2 \mathrm{D}$ guide in the case of the location of the maximum point of pressure in the heel (Figure 8). 
TABle 4: Student's $t$-test analysis of the features in male subjects F1 and F4 during 3 sessions with the $2 \mathrm{D}$ guide $(P>.000125 \rightarrow$ ",+ , $P<$ $.000125 \rightarrow$ “-”)

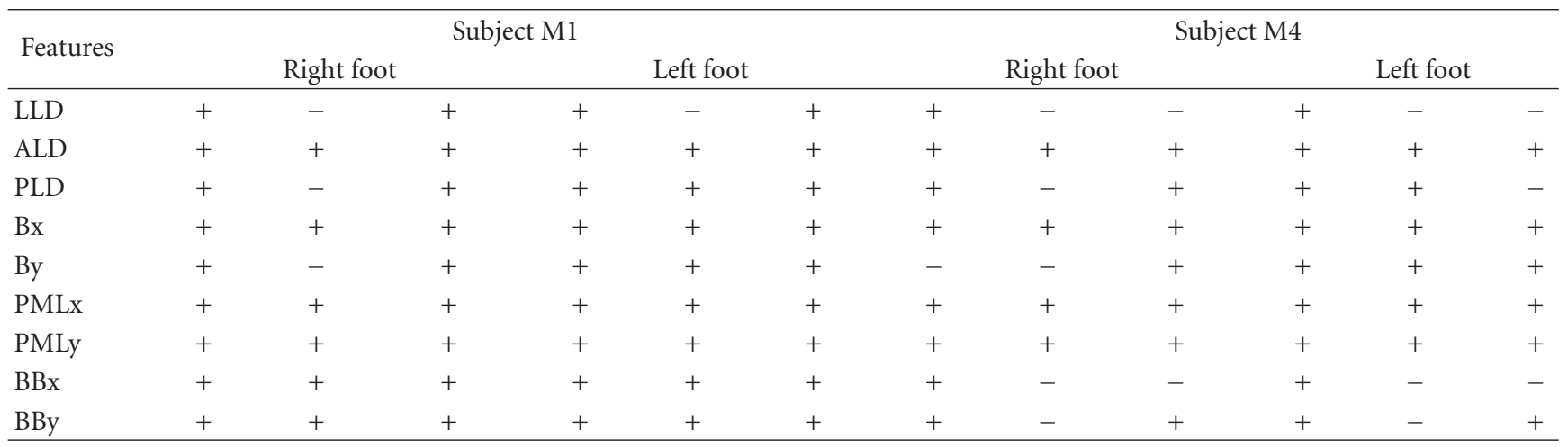
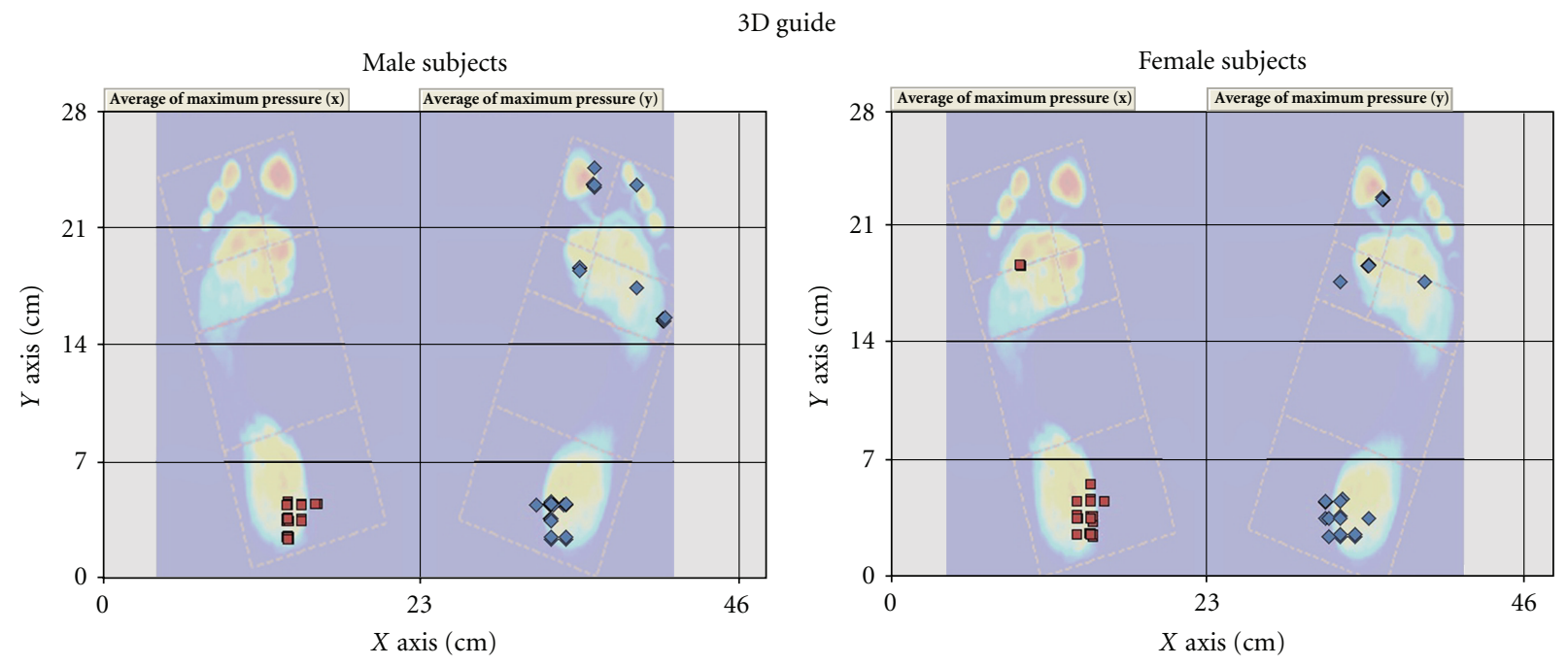

(a)

$2 \mathrm{D}$ guide
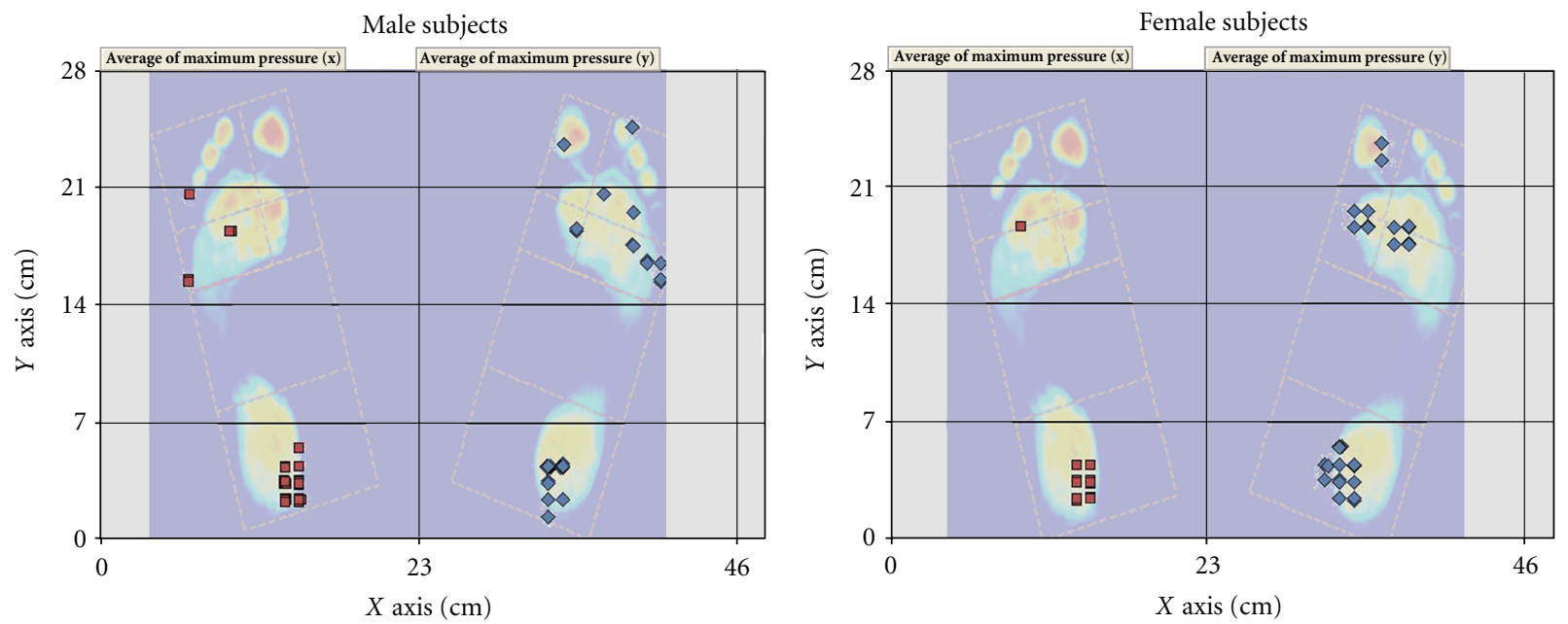

(b)

FIGURE 8: Pressure distribution patterns, including maximum pressure. 
3D guide
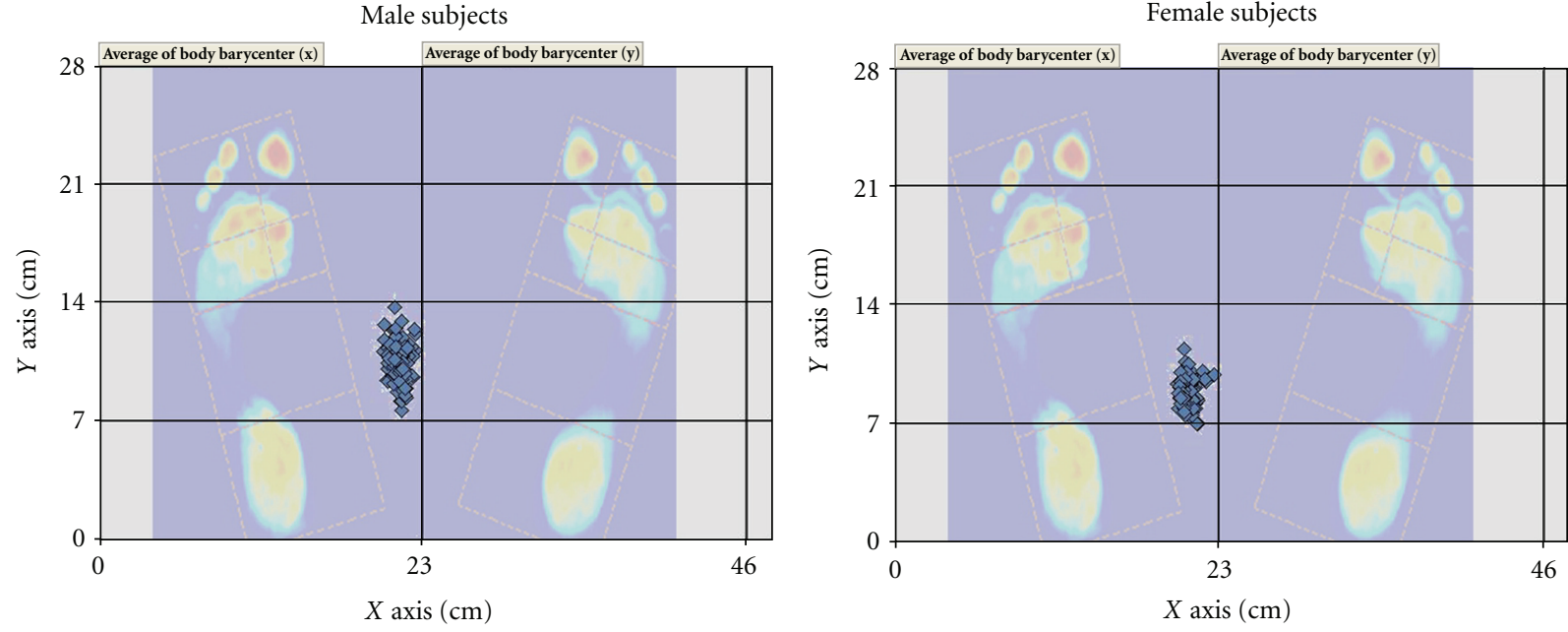

(a)

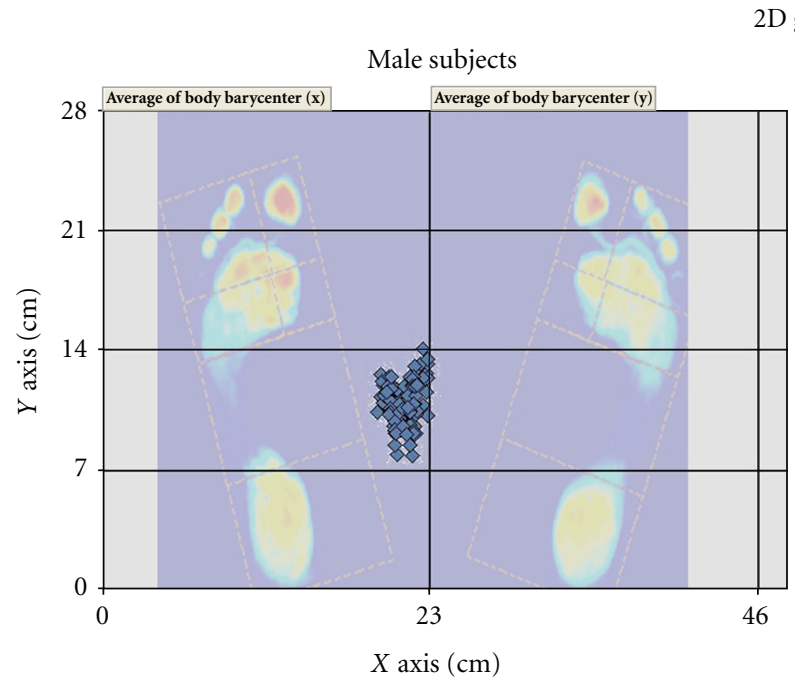

D guide

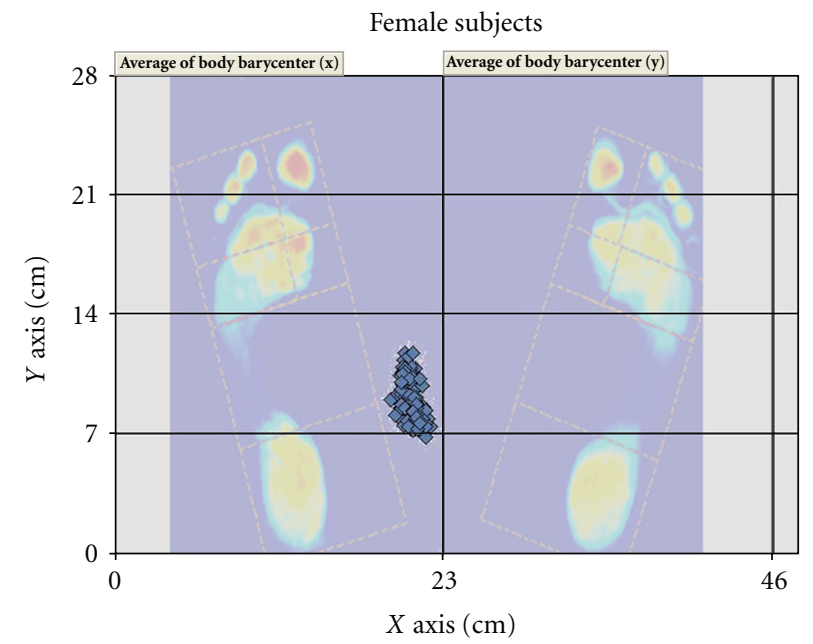

(b)

FIgURE 9: Body barycenter distributions.

The body barycenter graphs (Figure 9) show that, in all subjects and with both guides, $100 \%$ of the measurements are located to the left of the guide center. This behavior is also evidenced in the percentage of load distribution per foot (Tables 1 and 2), which shows greater load on the left foot. A higher dispersion is also shown when the $2 \mathrm{D}$ guide is used.

In the case of barycenter per foot (Figure 10), less dispersion of the data is observed when the $3 \mathrm{D}$ guide is used.

Table 7 summarizes the results obtained from the plantar pressure means for each case. The differences shown by the variables are not significant when data between guides and data for both genders are compared.

\section{Discussion}

Following the statistical analysis with Student's $t$-test, we noticed that the $3 \mathrm{D}$ wooden frame technique used for taking measurements with the Loran Platform for most of the male subjects, in various sessions during the three weeks of the study, was not a significant variable for pressure distribution and balance control. Only in the case of subject M4 were significant differences reported over the time for six variables with $P<.000125$. These results allow us to conclude that this technique favors registration of repeatable measurements, because it guarantees the same anatomical position of the feet during the measurements, although significant differences were reported in some variables in female cases, specifically with the LLD variable. Some variations were also observed between the left foot and right foot measurements, which were reported in Section 3.

After statistical analysis with Student's $t$-test, and with the $2 \mathrm{D}$ frame technique used to take measurements with the Loran Platform for subjects M1 and M2, we observed that time was not a significant variable for pressure distribution 


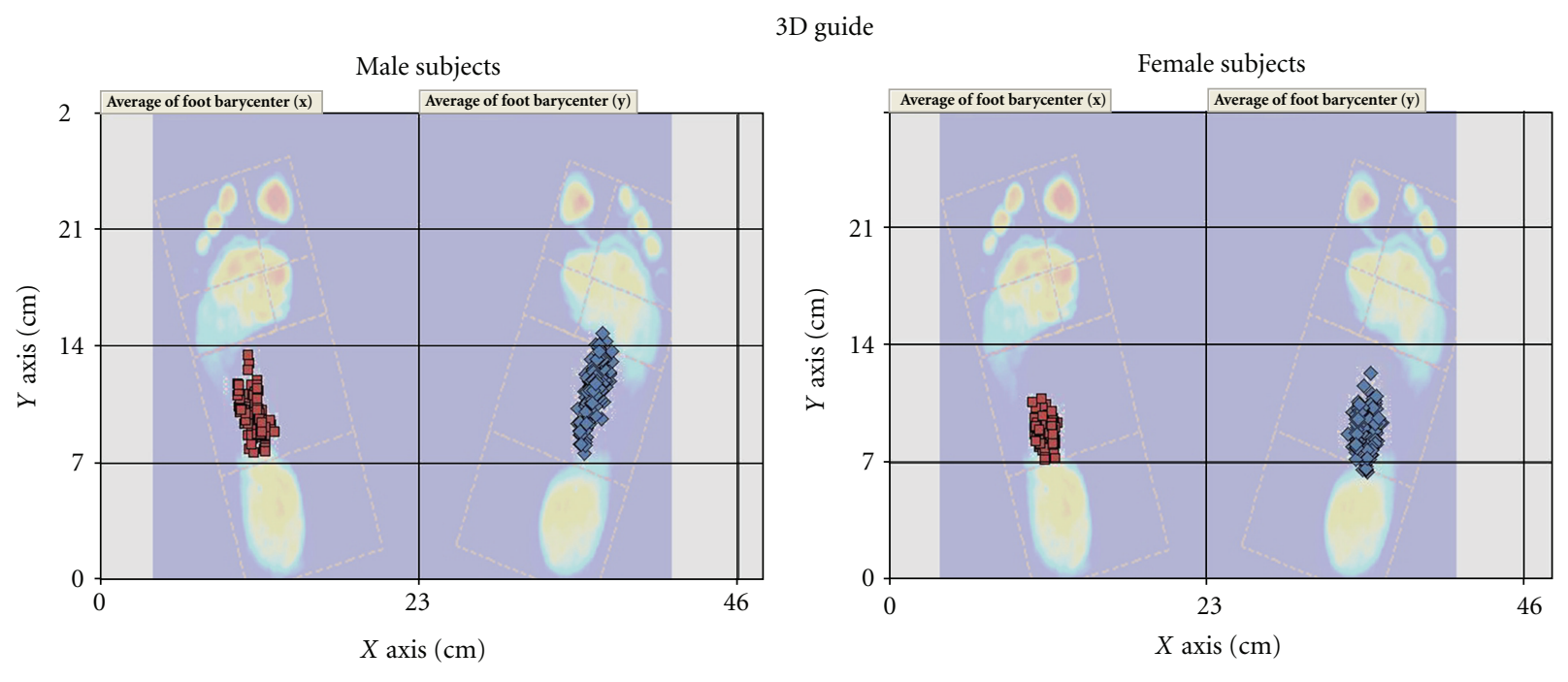

(a)

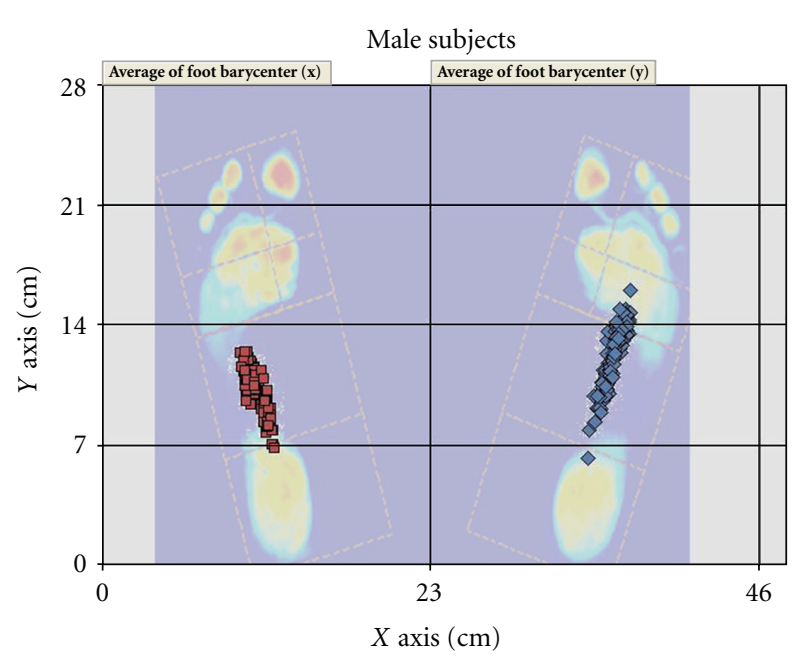

$2 \mathrm{D}$ guide

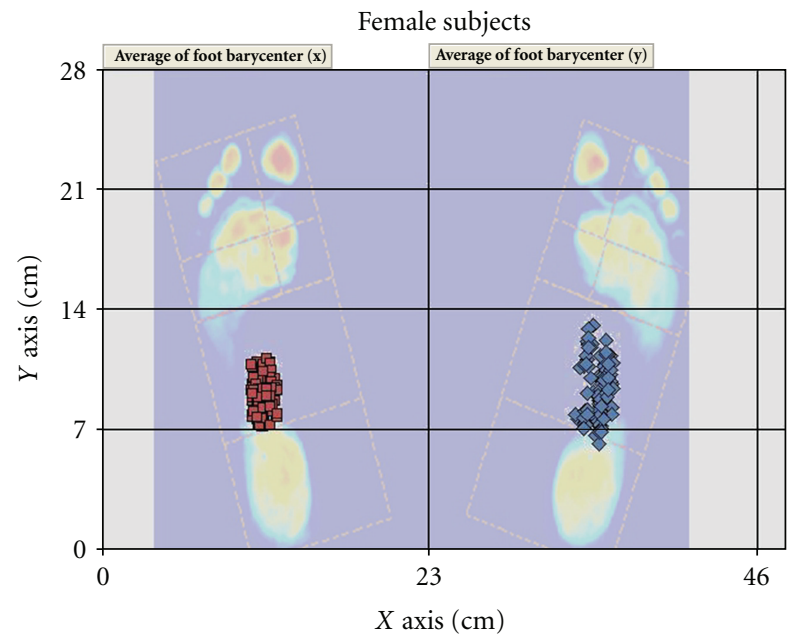

(b)

Figure 10: Foot barycenter distributions.

and balance control; however, subject M3 reported significant differences over time in four variables, and subject M4 reported significant differences over time in six variables. Female subjects reported significant differences in more variables, specifically variables LLD and PLD. These results lead us to believe that the $2 \mathrm{D}$ technique induces higher variability than the 3D technique when repeatable measurements are of concern, since the 2D technique does not guarantee the same position of the feet in the measurement sessions.

The ANOVA statistical analysis with the 3D wooden frame technique indicates that variables Bx, PMLx and BBx for male subjects and variables PMLx, and PMLy for female subjects presented higher variability in measurements among subjects, compared to measurements taken from the same subjects in the three sessions, because they reported $P<.001$. This means that the 3D technique makes it possible to obtain repeatable measurements when recording the variables evaluated in this study. The $2 \mathrm{D}$ frame technique indicates that variables PLD, By, PMLx, and BBy for male subjects and variables $\mathrm{Bx}$ and PMLx for female subjects showed higher variability in measurements among subjects compared with measurements taken from the same subjects in the three sessions, since they reported $P<.001$.

The above results indicate that the use of the 3D wooden frame technique used to register plantar pressure and balance control with the Loran Platform produced less variation among same subject measurements over the course of the measurement sessions and higher variability between measurements in other subjects. Better results for the acquisition of repeatable measurements are observed with the 3D technique compared with the 2D technique.

The load distribution pattern (LLD) through the three measurement sessions for male and female subjects (Figure 1), with 3D wooden frame guide in each foot, did 
TABLE 5: ANOVA test analysis sample of the most repeatable features. (a) Male subjects, (b) female subjects.

(a)

\begin{tabular}{lcc}
\hline & 3D guide & \\
Features & Right foot & Left foot \\
\hline Bx & $2,52 E-19$ & $1,41 E-44$ \\
PMLx & $6,50 E-05$ & $2,19 E-29$ \\
BBx & $1,66 E-13$ & $1,66 E-13$ \\
\hline
\end{tabular}

(b)

\begin{tabular}{lcc}
\hline & 3D guide & \\
Features & Right foot & left foot \\
\hline PMLx & $1,56 \mathrm{E}-07$ & $8,22 \mathrm{E}-10$ \\
PMLy & $5,68 \mathrm{E}-13$ & $7,092 \mathrm{E}-05$ \\
\hline
\end{tabular}

TABle 6: ANOVA test analysis sample of the most repeatable features. (a) Male subjects, (b) female subjects.

(a)

\begin{tabular}{lcc}
\hline & 2D guide & \\
Variable & Right foot & Left foot \\
\hline PLD & $2,28 E-22$ & $6,11 E-21$ \\
By & $3,2 E-22$ & $2,58 E-20$ \\
PMLx & $5,33 E-15$ & $2,99 E-05$ \\
PMLy & $8,88 E-12$ & 0,0226 \\
BBy & $4,25 E-16$ & $4,25 E-16$ \\
\hline
\end{tabular}

(b)

\begin{tabular}{lcc}
\hline & 2D guide & \\
Variable & Right foot & Left foot \\
\hline Bx & $1,35 E-34$ & $2,997 E-33$ \\
PMLx & 0,00039 & $2,706 E-12$ \\
PMLy & $9,48 E-08$ & 0,0822 \\
\hline
\end{tabular}

not show significant variability; an almost linear tendency is observed in both cases. On the other hand, the 2D frame technique showed higher variability in load distribution (Figure 2). This less variable pattern with the $3 \mathrm{D}$ guide may be used as a foundation to validate the hypothesis used in this study, whereby controlling the position of the feet when measuring plantar pressure makes it possible to acquiring more repeatable measurements. Comparing measurements taken from both feet, there were differences between left foot and right foot in all subjects. It is possible that other factors such as age, weight, height, and posture may impact the distribution of loads on each foot in the subjects evaluated.

In Figure 8, certain differences exist due to a smaller dispersion in the points of maximum pressure in the metatarsals. These are areas of interest for future studies with diabetic foot patients, because those areas are subject to a higher risk of ulceration, in turn associated with postural balance control in the bipedal position.

Figures 9 and 10 of the body barycenter (BB) and of the foot barycenter (B), respectively, indicate the pattern similarity with the two guide types. Greater differences exist when comparing the behavior of the left foot barycenter and the right foot barycenter, normal behavior, given the right side dominance of all subjects participating in the study, with a higher percentage of load distribution on the left foot. Regarding gender comparison, Figure 5 shows a better concentration in women, near the heel, while in men, the barycenter is dispersed along the half line of the foot.

\section{Conclusions}

This pilot study establishes that the Loran Platform makes it possible to obtain repeatable measurements for the following variables: percentage of load for each foot (LLD), body barycenter (BBx and BBy), foot barycenters (Bx and By), and point of maximum pressure, for the evaluation of the plantar pressure distribution and balance control in normal subjects.

The $3 \mathrm{D}$ wooden frame technique favors registration of repeatable measurements because it guarantees the same anatomical position of the feet when measurements are recorded. Student's $t$-test results indicate that the time variable does not significantly affect repeatability of the measurements; the ANOVA statistical analysis reports less variation between the measurements of the same subject over the course of the measurement sessions and greater variability among the measurements of other subjects. The 3D technique produces better results for acquisition of repeatable measurements than the $2 \mathrm{D}$ technique.

Men and women differ anatomically and physiologically. Anthropometric studies have shown considerable differences in the feet bones of both genders [9]. These differences may potentially mean male versus female differences in plantar distribution, such as the differences found in this study. Besides, there are studies reporting the influence of age on the dynamic variation of the center of gravity displacementCOP_-in the bipedal position [10].

Studies of plantar pressure using an in-shoe system and a pressure platform [11] have reported that differences in the results of plantar pressure distribution among various groups may also be attributed to measurement conditions and effects produced by the measurement system used. We consider this study to be relevant because the technique can be used to record pressure with the Loran Engineering EPS platform in normal subjects. However, new experiments with diabetic patients must be performed to ensure the reliability of this platform in reproducing repeatable measurements, for possible application in a clinical environment.

In selecting the target population for this study, it was fundamental to include previous osteomuscular type evaluation, with special emphasis on the spine, when subjects were over 40 years old; it has been reported [12] that plantar pressure distribution may be affected by balance problems associated with age and spinal problems usually accompanied by lumbar discomfort caused by maintaining the bipedal position over prolonged periods of time.

Previous investigations [13] have demonstrated that there is an important decrease of "standing balance" in neuropathic patients with the diabetic foot. This means that balance control is a fundamental biomechanical parameter for the diagnosis of the diabetic foot. For this reason, we 
TABLE 7: 3D guide and 2D guide results-female and male subjects.

\begin{tabular}{|c|c|c|c|c|}
\hline \multirow{3}{*}{ Features } & \multirow{2}{*}{\multicolumn{2}{|c|}{ Male $($ mean $+S D)$}} & \multirow{2}{*}{\multicolumn{2}{|c|}{ Female $($ mean $\pm S D)$}} \\
\hline & & & & \\
\hline & Right foot & Left foot & Right foot & Left foot \\
\hline $\operatorname{LLD}(\%)$ & $41.28 \pm 1.56$ & $58.72 \pm 1.56$ & $40.7 \pm 2.1$ & $59.3 \pm 2.1$ \\
\hline $\mathrm{Bx}(\mathrm{cm})$ & $4.88 \pm 0.33$ & $4.12 \pm 0.45$ & $4.71 \pm 0.62$ & $3.76 \pm 0.45$ \\
\hline By $(\mathrm{cm})$ & $10.94 \pm 1.62$ & $8.6 \pm 1.19$ & $8.5 \pm 1.18$ & $7.62 \pm 0.73$ \\
\hline ALD (\%) & $19.88 \pm 4.11$ & $23.07 \pm 4.36$ & $14.59 \pm 3.21$ & $21.8 \pm 2.12$ \\
\hline PLD (\%) & $21.39 \pm 4.62$ & $35.66 \pm 4.12$ & $26.11 \pm 3.96$ & $37.5 \pm 3.12$ \\
\hline \multicolumn{5}{|c|}{ 2D guide } \\
\hline \multirow{2}{*}{ Features } & \multicolumn{2}{|c|}{ Male $($ mean $\pm S D)$} & \multicolumn{2}{|c|}{ Female $($ mean $\pm S D)$} \\
\hline & Right foot & Left foot & Right foot & Left foot \\
\hline $\operatorname{LLD}(\%)$ & $40.66 \pm 2.01$ & $59.34 \pm 2.01$ & $39.73 \pm 2.48$ & $60.28 \pm 2.1$ \\
\hline $\mathrm{Bx}(\mathrm{cm})$ & $4.89 \pm 0.24$ & $3.96 \pm 0.28$ & $4.64 \pm 0.77$ & $3.83 \pm 0.58$ \\
\hline By $(\mathrm{cm})$ & $11.27 \pm 1.63$ & $8.49 \pm 1.32$ & $9.09 \pm 1.49$ & $7.67 \pm 0.97$ \\
\hline ALD (\%) & $20.48 \pm 4.69$ & $24.15 \pm 5.1$ & $15.03 \pm 3.15$ & $22.77 \pm 3.2$ \\
\hline PLD (\%) & $20.18 \pm 3.92$ & $35.19 \pm 4.88$ & $24.7 \pm 4.57$ & $37.5 \pm 3.24$ \\
\hline
\end{tabular}

consider it imperative to replicate this study in the future using neuropathic diabetic patients in various stages of complications of the feet.

This study must be repeated with a much larger sample to ensure statistical validation, using groups of normal subjects and diabetic foot patients in the first stages of the pathology, in both static and dynamic conditions. This will greatly assist optimization in the design of orthopedic insoles which normalize plantar distribution in areas subject to higher risk of ulceration (metatarsal heads, fingers, and heel).

Finally, we recommend optimizing measurement protocols and designing techniques for postural control of study subjects, for the evaluation of plantar distribution and stability.

\section{Acknowledgments}

We sincerely acknowledge the efforts of the staff at the Orthopedics Department of San Ignacio Hospital in Bogotá, Colombia, for their help in recruiting suitable subjects for this study, and express our gratitude to all study participants. We are grateful to Javeriana University for academic and financial support of this study. Dr. Zequera would like to sincerely thank Professor Ken Paterson, Consultant Physician, Glasgow Royal Infirmary, for his encouragement, professional advice, and financial support, and Professor Stephan Solomonidis, Biomechanics expert, Bioengineering Unit, Strathclyde University, U.K.

\section{References}

[1] A. Bener, M. Zirie, I. M. Janahi, A. O. A. A. Al-Hamaq, M. Musallam, and N. J. Wareham, "Prevalence of diagnosed and undiagnosed diabetes mellitus and its risk factors in a population-based study of Qatar," Diabetes Research and Clinical Practice, vol. 84, no. 1, pp. 99-106, 2009.
[2] A. Agić, V. Nikolić, B. Mijović, and U. Reischl, "Biomechanical model of the diabetic foot," Collegium Antropologicum, vol. 32, no. 3, pp. 881-886, 2008.

[3] M. Zequera, S. Stephan, and J. Paul, "The "PAROTEC" foot pressure measurement system and its calibration procedures," in 28th Annual International Conference of the IEEE (EMBS '06), pp. 4135-4139, Engineering in Medicine and Biology Society, September 2006.

[4] M. Zequera, S. Stephan, and J. Paul, "The position of the centres of the sensors of the parotec pressure measurement Insoles system related to the anatomy centres of the metatarsal heads by means of radiological records ," in 29th Annual International Conference of the IEEE (EMBS '07), pp. 44534456, Engineering in Medicine and Biology Society, August 2007.

[5] M. Maetzler, T. Bochdansky, and R. J. Abboud, "Normal pressure values and repeatability of the Emed(R ST2 system," Gait and Posture, vol. 32, no. 3, pp. 391-394, 2010.

[6] J. K. Gurney, U. G. Kersting, and D. Rosenbaum, "Betweenday reliability of repeated plantar pressure distribution measurements in a normal population," Gait and Posture, vol. 27, no. 4, pp. 706-709, 2008.

[7] R. Lomas Vega and M. C. López Ruiz, "Stabilometry and quality of life in the spinal pain. An analytic transversal study," Fisioterapia, vol. 27, no. 3, pp. 129-137, 2005.

[8] A. C. Redmond, K. B. Landorf, and A. Keenan, "Contoured, prefabricated foot orthoses demonstrate comparable mechanical properties to contoured, customised foot orthoses: a plantar pressure study," Journal of Foot and Ankle Research, vol. 2, no. 1, 2009.

[9] A. B. Putti, G. P. Arnold, and R. J. Abboud, "Foot pressure differences in men and women," Foot and Ankle Surgery, vol. 16, no. 1, pp. 21-24, 2010.

[10] T. L. Chevalier, H. Hodgins, and N. Chockalingam, "Plantar pressure measurements using an in-shoe system and a pressure platform: a comparison," Gait and Posture, vol. 31, no. 3, pp. 397-399, 2010. 
[11] B. Seigle, S. Ramdani, and P. L. Bernard, "Dynamical structure of center of pressure fluctuations in elderly people," Gait and Posture, vol. 30, no. 2, pp. 223-226, 2009.

[12] D. Lafond, A. Champagne, M. Descarreaux, J. D. Dubois, J. M. Prado, and M. Duarte, "Postural control during prolonged standing in persons with chronic low back pain," Gait and Posture, vol. 29, no. 3, pp. 421-427, 2009.

[13] R. V. Kanade, R. W. M. Van Deursen, K. G. Harding, and P. E. Price, "Investigation of standing balance in patients with diabetic neuropathy at different stages of foot complications," Clinical Biomechanics, vol. 23, no. 9, pp. 1183-1191, 2008. 

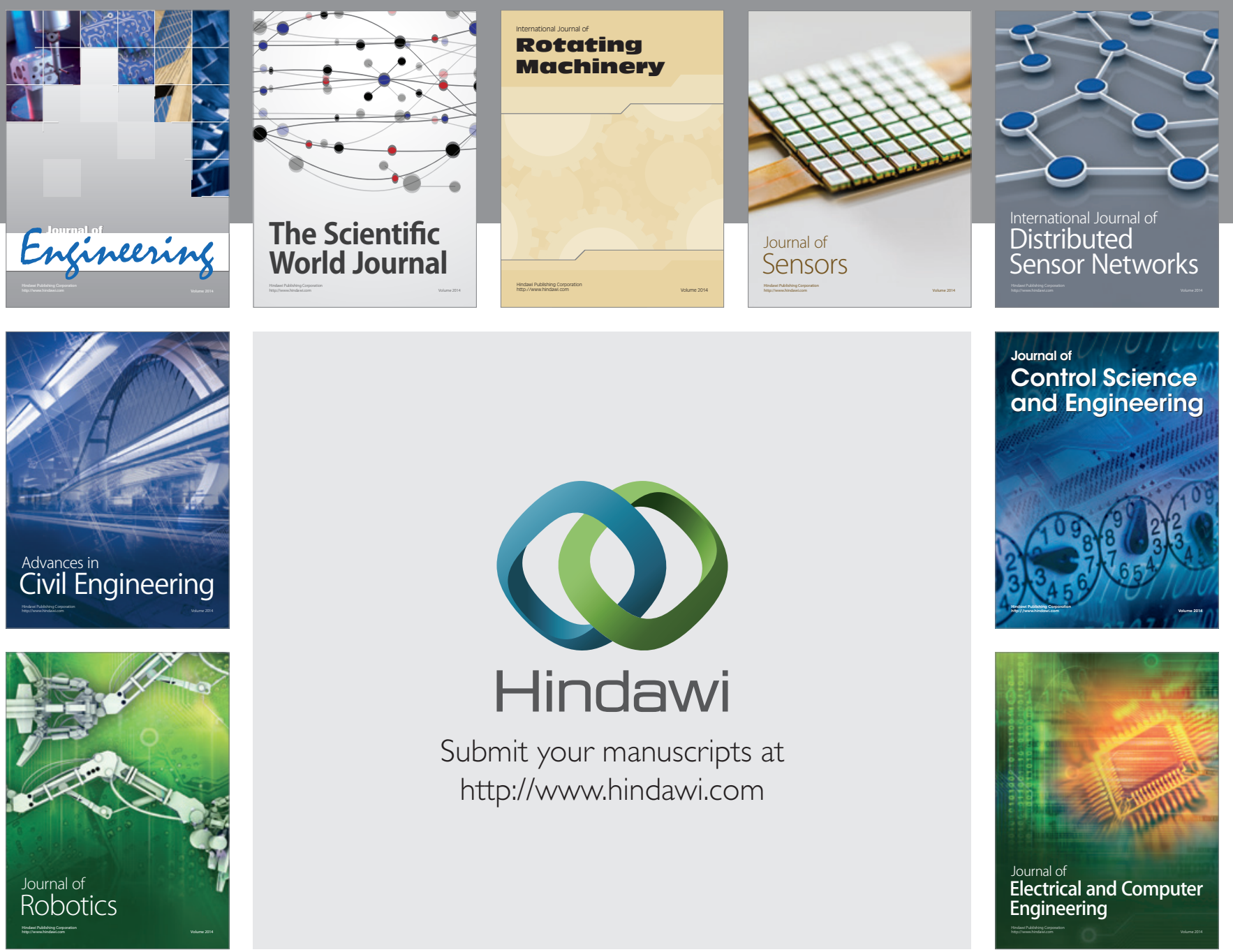

Submit your manuscripts at

http://www.hindawi.com
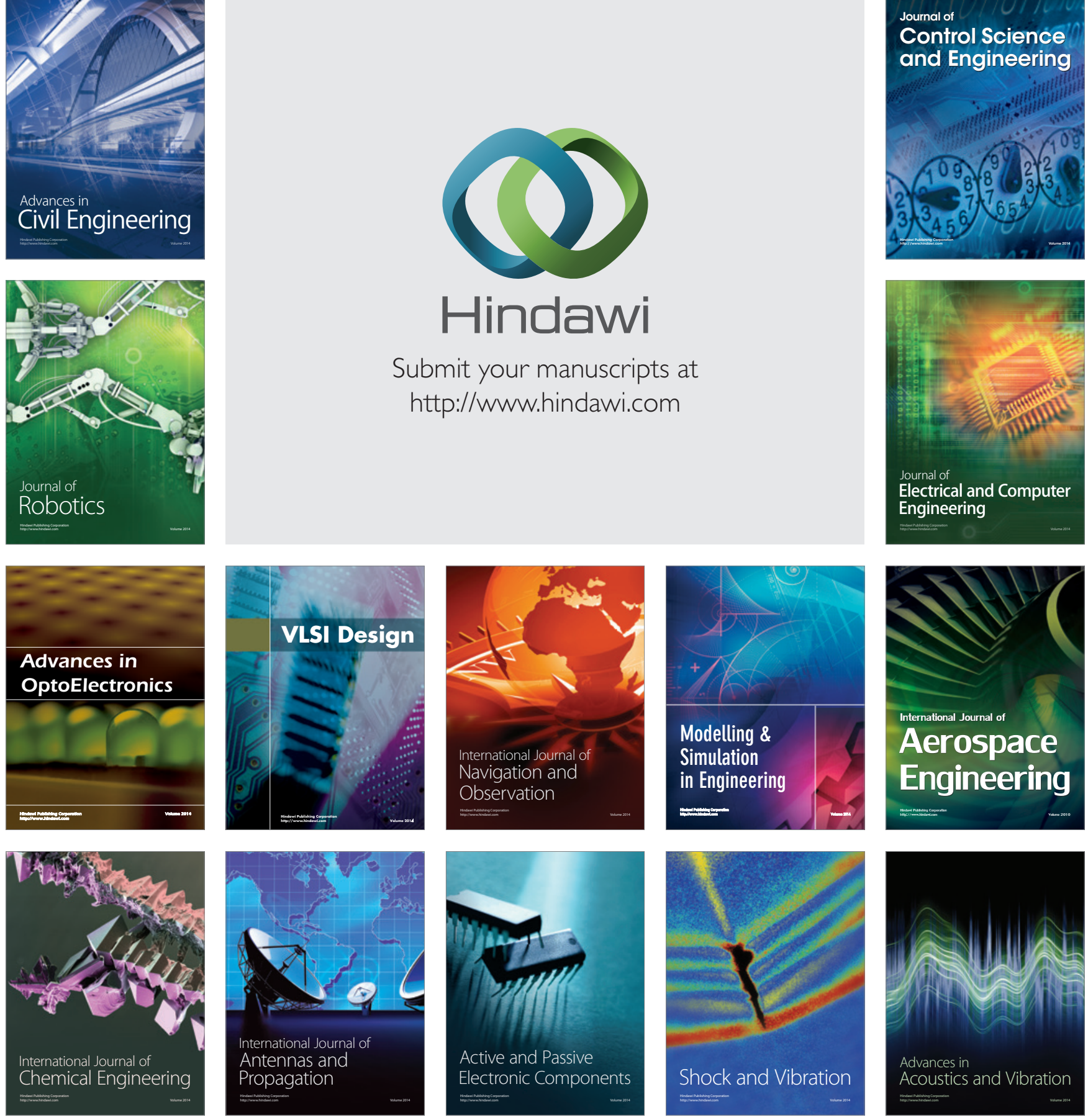